\title{
Study on Electrical Properties of PALF Reinforced Bisphenol-A Composite
}

\author{
$\operatorname{Vinod~B.}{ }^{1^{*}}$ and L. J. Sudev ${ }^{1}$ \\ ${ }^{1}$ Department of Mechanical Engineering, VVCE, Mysuru, India
}

\begin{abstract}
These days, composite materials successfully substitute the traditional materials due to its various significant applications. This paper examines the influence of fiber orientation and fiber length on electrical properties of PALF reinforced Bisphenol-A composite and explores the potential of using PALF as reinforcing material for electrical applications such as terminals, connectors, motor body cover, industrial and household plugs and circuit boards. The resistance and inductance of resin material is increased by $24.19 \%$ and $24.13 \%$ respectively after reinforcement of PALF in different orientations and its value increased by $37.93 \%$ and $37.81 \%$ respectively after reinforcement of PALF in different lengths. Similarly, Capacitance and Dielectric constant of resin material decreased by $19.44 \%$ and $19.39 \%$ respectively after reinforcement of PALF in different orientations and its value decreased by $27.67 \%$ and $27.50 \%$ respectively after reinforcement of PALF in different lengths. It can be inferred from this study that the fiber orientations and fiber lengths greatly effects the electrical properties of PALF composite.
\end{abstract}

Keywords: Pineapple leaf fiber, Bisphenol-A, Capacitance, Resistance, inductance, volume resistivity.

\section{Introduction}

Natural fiber reinforced polymer composite has attracted the interest of many of the researchers for developing competing material towards conventional material. These composite materials offer high strength to weight ratio, higher performing ability, easy in manufacturing, low cost and low density. Natural fibers are easily available, cheaper, environmental friendly and most of these fibers are wasted by burning out after extraction of fruits or vegetables, which lead to pollution of air. It is necessary to develop the newer material that is friendly towards environment, easily degradable, renewable and to be a substitution for depletion of conventional resources. Usually the natural fiber is from agricultural source, it is possible to modify the final properties of the composite material by selection of suitable fibers with a given chemical or morphological composition. In future, composites reinforced by natural fiber form a new class of materials and seem to have good potential in future as a standby for metals and wood based materials for structural applications of various small and large scale industries. [1,2].

\footnotetext{
*Corresponding author: vinod@vvce.ac.in
} 
India holds the second largest agricultural land in the world with diversified topography. Nearly $70 \%$ of population lead their livelihood from agriculture. The eatables that obtained from agriculture are basic need of human beings and animals and also a major source for various agro-based industries. The final products which are left out such as leaf, stem, roots etc. are burnt in most of the situations after extractions of useful products. One such commonly known fruit plant is pineapple. Even though being mechanically sound and environmentally excellent, pineapple leaves from which pineapple leaf fiber (PALF) are extracted are burnt or wasted after extraction of fruits. Though it is extensively used as textile material, it is the least studied fiber as reinforcement for composite material. Table 1 shows the chemical composition of PALF. The climatic condition, oldness of fibers, method of extraction and source of fibers are some of the factors responsible for varying composition of PALF. The most important of these is lignin, which acts as a cementing material by bonding different cells in plant fibers together. The lignin content in fiber obtained from plants impact on its structural properties and morphology. The cellulose fibrils embedded in lignin matrix of plant fibers is responsible for its high electrical resistance. This high electrical resistance property of the fiber can be utilized for manufacturing various industrial components such as switch board, PCB plates, terminals, connectors, switches, plugs and motor coverings etc. suitable for various electrical engineering applications by incorporating in polymer matrix material. The suitability of composite material for such electrical applications is determined by testing its properties in terms of resistance, inductance, capacitance and dielectric constant.

Table 1. Chemical composition of Pineapple Leaf Fiber (PALF)

\begin{tabular}{|c|c|c|}
\hline SI No. & Chemical Composition & Proportion \\
\hline 1. & Cellulose & $67.12-82 \%$ \\
\hline 2. & Hemicelluloses & $9.45-18.80 \%$ \\
\hline 3. & Lignin & $4.4-15.4 \%$ \\
\hline 4. & Pectin & $1.2-3 \%$ \\
\hline 5. & Fat and Wax & $3.2-4.2 \%$ \\
\hline
\end{tabular}

\section{Literature Survey}

In most of the literature it is emphasized that natural fiber reinforced polymer composites shows better electrical resistance property and can be best suited for most of the electrical engineering applications. Navin Chand et al. [3] made investigation on the influence of fibre orientation on electrical properties of epoxy composites reinforced with sisal fiber. Sisal fibers are oriented parallel and perpendicular to the electric field. He concluded that sisal fibre reinforced polysulphide modified epoxy composites shows electrical anisotropic behaviour and Dielectric constant anisotropy decreases with frequency. P. A. Sreekumar et al. [4] made investigation on influence of short sisal fiber on electrical properties of polyester composites. The composites are fabricated by resin transfer moulding (RTM) technique with respect to percentage of fiber, frequency and temperature. The dielectric constant $(\varepsilon ')$, loss factor $(\varepsilon ')$, dissipation factor $(\tan \delta)$ and conductivity increases with fiber content for the entire range of frequencies. The composites with $50 \%$ of fiber content shows better results due to the increment in orientation and interfacial polarizations resulting from the presence of polar groups of cellulose in natural fibers. Govardhan Goud et al. [5] made experimental studies on electrical properties of epoxy hybrid composite reinforced by Roystonea regia/glass fibre. He concludes that blending glass fiber with natural fibers leads to decrease in conductivity and dielectric constant at all frequency. 


\section{Materials and Methodology}

\subsection{Pine Apple Leaf Fiber (PALF)}

PALF is extracted through anaerobic process, where pineapple leaf is soaked in water for 3 to 4 days in specially designed soaking tank connected with anaerobic reactor in which temperature between $20^{\circ}$ to $37^{\circ} \mathrm{C}$ and neutral $\mathrm{pH}$ of 6.7 to 8 is maintained. During the reaction, pectin the intercellular cementing matter present around the PALF fiber get degraded. This results in split-up of fibers from their surroundings. These fibers can be extracted easily without any damage when compared with other mechanical process for extraction of fibers [6].

\subsection{Bisphenol-A}

Bisphenol-A (BPA) is also called as Diglycidyl Ether of Bisphenol-A (DGEBA). It is an organic compound which belongs to the group of diphenylmethane derivatives and Bisphenol. BPA resin offers superior manufacturing flexibility, better adhering ability, excellent mechanical property, better resistance to fatigue and micro cracking, lower degradation from water ingress and improved resistance to osmosis. These properties made to choose BPA as matrix material [7].

\subsection{Preparation of Sample}

After extraction of fibers from pineapple leaf it is subjected for chemical treatment in order to improve adhering ability of the fibers by making its surface rough and to remove impurities. The treated fibers are ready to use as reinforcing material for preparation of composite laminates. The laminates are prepared for different fiber orientations like Unidirectional, Bi-directional and inclined at an angle of $45^{\circ}$ as shown in Fig. 1. The manufacturing of composites by reinforcing with short fibers offers more flexibility than the long fibers. Hence laminates are prepared from fiber lengths ranging from $2 \mathrm{~mm}$ to 14 $\mathrm{mm}$ with step size of $2 \mathrm{~mm}$ in random orientations using hand layup method. Composite laminates are cut into test specimens of required size as per ASTM standards.

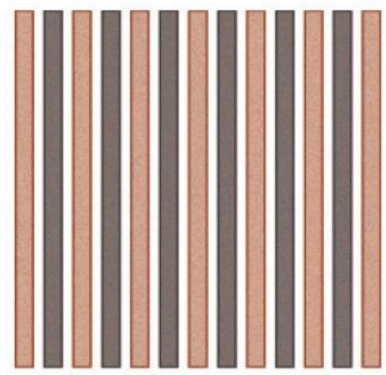

Fig. 1. (a) Uni-directional

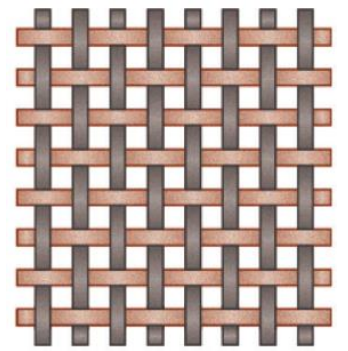

(b) Bi-directional

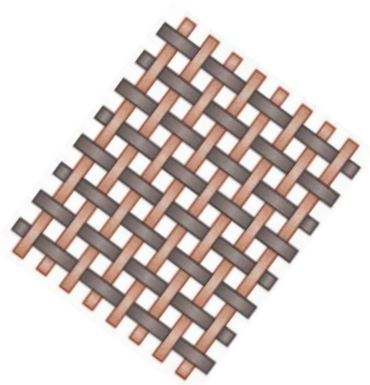

(c) $45^{0}$ oriented fibers

\subsection{Experimentation}

The electrical application of composite material makes it important to investigate electrical properties of composite. The resistance, inductance, capacitance and dielectric constant are some of the important electrical properties for different electrical applications of composite. Electrical resistance is a very important property of material for using it as electrical insulators. The resistance of the composite is calculated using an instrument called Megger. 
Initially the instrument is peddled to energize the coil and peddling is continued at a constant speed till the needle showed a constant value of resistance. Using resistance value the other parameters like inductance, capacitance, dielectric constant, volume resistivity, dielectric dissipation factor are calculated using mathematical relationships as follows.

a) Inductance: It is a measure of an inductors 'resistance' to change in current flowing through the circuit. Good power factor (PF) plays a major role for correct operation of a power system. For very lower value of power factor an electrical system may suffer from excessive losses and poor voltage regulation. Also the inductors are used in filters, sensors, transformers, motors. Thus inductance plays a significant role in designing and varying the performance of the circuits and devices. The SI unit is Henry. Where $\mathrm{R}$ is resistance and $\mathrm{L}$ is inductance.

$$
R=\frac{1}{\sqrt{R^{2}+(2 \pi f L)^{2}}}
$$

b) Capacitance: It is an ability of a body to store an electrical Charge. It can be used to improve the power factor. The SI unit of capacitance is Farad. Where R is resistance and $\mathrm{C}$ is capacitance.

$$
R=\frac{1}{\sqrt{R^{2}+\frac{1}{(2 \pi f C)^{2}}}}
$$

c) Dielectric constant: The dielectric property decides the storage and dissipation of electric and magnetic energy in materials. Higher the dielectric constant is the greater the resistance it will impose upon the changing electric field. The various phenomenons in electronics, optics, and solid-state physics can be explained with the help of dielectrics property.

$$
\varepsilon=\frac{C t}{\varepsilon_{0} A}
$$

where, $\varepsilon_{o}$ - Permittivity of air $\left(8.85 \times 10-12 \mathrm{Fm}^{-1}\right)$, C - Capacitance (F), A - Area of cross-section of the sample $\left(\mathrm{m}^{2}\right)$ and $\mathrm{t}$ - Thickness of the sample $(\mathrm{m})$ [8].

\section{Results and Discussions}

\subsection{Electrical properties of PALF composite for different fiber orientations}

Some of the important electrical properties such as resistance, inductance, capacitance and dielectric constant are determined for PALF reinforced composite as discussed above. Table 2 shows the experimental results of Bisphenol-A resin material alone without any reinforcement and for the resin material reinforced with PALF long fibers in different orientations. The values given in the table are the averaged values from 3 trials. 
Table 2. Electrical properties of Resin and PALF composite in different fiber orientations

\begin{tabular}{|c|c|c|c|c|c|}
\hline $\begin{array}{c}\text { Sl } \\
\text { no }\end{array}$ & Fiber orientation & $\begin{array}{c}\text { Resistance } \mathbf{R} \\
(\mathbf{M} \mathbf{\Omega})\end{array}$ & $\begin{array}{c}\text { Inductance L } \\
\mathbf{( k H )}\end{array}$ & $\begin{array}{c}\text { Capacitance C } \\
\mathbf{( p F})\end{array}$ & $\begin{array}{c}\text { Dielectric } \\
\text { constant } \boldsymbol{\varepsilon}\end{array}$ \\
\hline 1 & $\begin{array}{c}\text { Bisphenol-A } \\
\text { (Without any fibers) }\end{array}$ & 145 & 461.55 & 21.91 & 7.07 \\
\hline \multicolumn{5}{|c|}{ Bisphenol-A resin after reinforcement of PALF in different orientations. } \\
\hline 2 & Uni directional & 148 & 466.27 & 21.47 & 6.931 \\
\hline 3 & Bi - directional & 168 & 532.51 & 18.90 & 6.100 \\
\hline 4 & $45^{\circ}$ orientation & 180 & 572.96 & 17.65 & 5.699 \\
\hline
\end{tabular}

The variation of resistance of the unreinforced resin material and the resin reinforced with PALF in different orientations is shown in Fig. 2. Similarly, Fig. 3 shows variation of inductance. The change in capacitance and dielectric constant is depicted in Fig. 4 and 5 respectively.

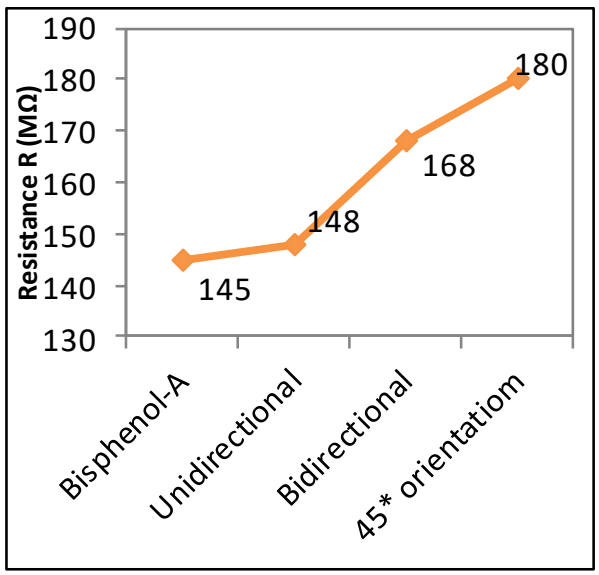

Fig. 2. Change in resistance for the resin $\&$ composite for different fiber orientation

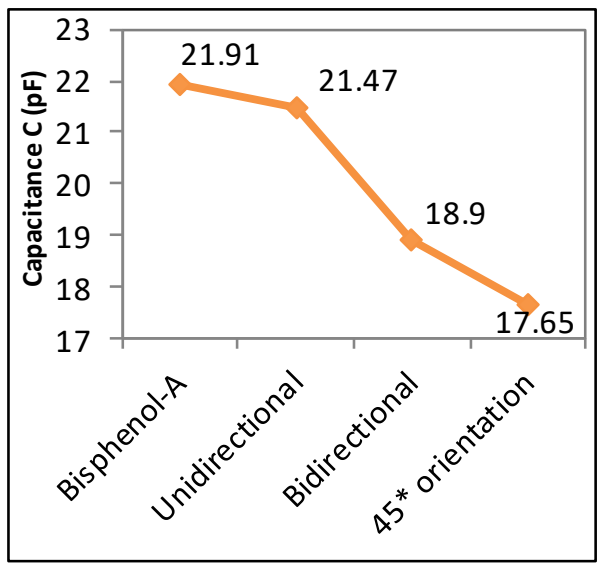

Fig. 4. Change in capacitance for the resin \& composite for different fiber orientation

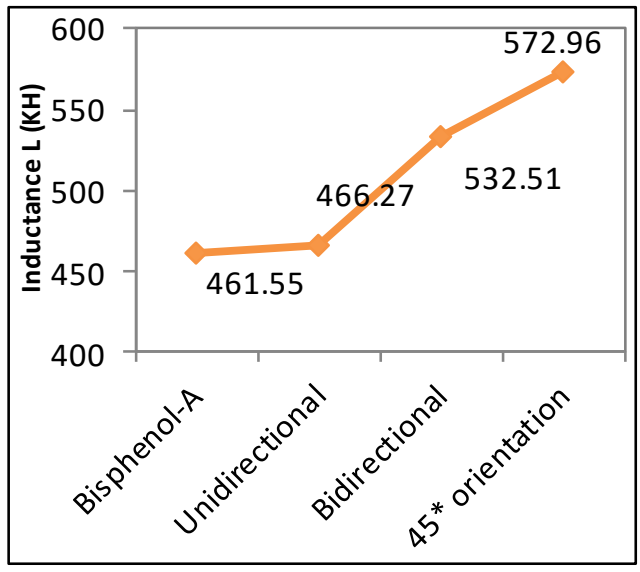

Fig. 3. Change in inductance for the resin \& composite for different fiber orientation

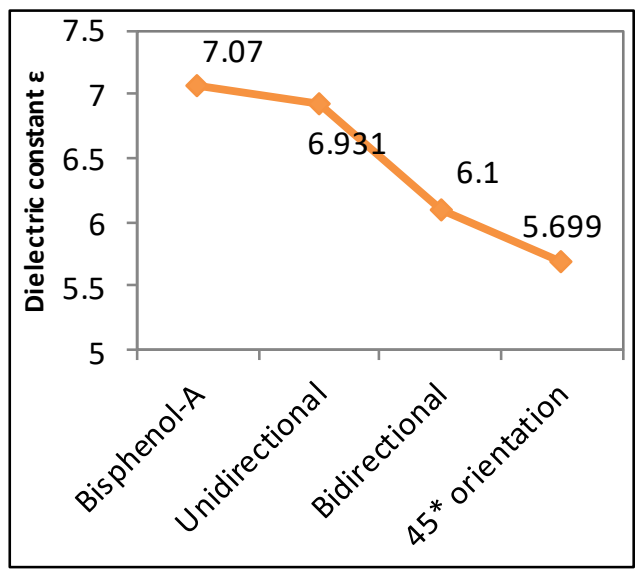

Fig. 5. Change in dielectric constant for the resin \& composite for different fiber orientation 
The electrical resistance and inductance of resin material is $145 \mathrm{M} \Omega$ and $461.55 \mathrm{kH}$ respectively and its value increases gradually after reinforcement of PALF in different orientations. The maximum value of $180 \mathrm{M} \Omega$ and $572.96 \mathrm{kH}$ respectively is obtained for the composite with fiber orientation of $45^{\circ}$ which is $24.13 \%$ and $24.23 \%$ greater than resin material without any reinforcement. The resistivity of the composites depends on percentage of water content in fiber, impurities, micro fibril angle, cellulosic structure etc. After extracting fibers from leaf, it is subjected to alkaline treatment in order to remove fatties and any other impurities that present in the fibers. Treated fibers are dried in oven for $1 \mathrm{hr}$ whose temperature is maintained at $60^{\circ} \mathrm{C}$. Hence finally obtained fibers are free from impurities and moisture content, which decreases the electrical conductance of fiber reinforced composite. Further, $45^{\circ}$ oriented fiber arrangement brought the heterogeneity in to the composite. As a result of this, when electrical field is applied to the composite, $\mathrm{OH}-$ group presented in the cellulose of the PALF get polarized and trapped at the interfaces of heterogeneous system. Whereas, unidirectional fiber reinforced composite shows less heterogeneity.

The capacitance and Dielectric constant of resin material is $21.91 \mathrm{pF}$ and 7.07 respectively and its value decreases gradually after reinforcement of PALF in different orientations. The minimum value of $17.65 \mathrm{pF}$ and 5.699 respectively is obtained for the composite with fiber orientation of $45^{\circ}$ which is $19.44 \%$ and $19.39 \%$ lesser than resin material without any reinforcement. It is found that dielectric constant increases with the presence of impurities, moisture content in fiber (which leads to flexibility for movement of water dipole) and with increase of temperature. As already discussed reinforced fibers are free from impurities and water content leads to decrease of dielectric constant. The value of dielectric constant of any composites is influenced by polarizability of that composite material. Higher the polarizability of particle, higher will be dielectric constant [9]. Hence, less polarization of polar groups due to alkali chemical treatment, which removes hydrophilic nature that is polar groups from the fiber surface, is also responsible for the decrease in dielectric constant [10]. The decrease in capacitance and dielectric constant after the PALF reinforcement indicates the decrease in the ability of a body to store an electrical charge.

\subsection{Electrical properties of PALF composite for different fiber lengths}

The electrical behavior of the composites for different fiber lengths is carried out similar to the experiments conducted for composites with different fiber orientations as discussed above. Table 3 shows the experimental results of Bisphenol-A resin material alone without any reinforcement and for the resin material reinforced with short PALF fibers in different lengths. The change in resistance of resin material and the resin reinforced with PALF with change in fiber lengths is shown in Fig. 6. Similarly, Fig. 7 shows variation of inductance. The change in capacitance and dielectric constant is shown in Fig. 8 and 9 respectively. 
Table 3. Electrical properties of Resin and PALF composite in different fiber lengths

\begin{tabular}{|c|c|c|c|c|}
\hline Fiber lengths & $\begin{array}{c}\text { Resistance } \\
\mathbf{R}(\mathbf{M} \mathbf{)})\end{array}$ & $\begin{array}{c}\text { Inductance } \\
\mathbf{L}(\mathbf{K H})\end{array}$ & $\begin{array}{c}\text { Capacitance } \\
\mathbf{C}(\mathbf{p F})\end{array}$ & $\begin{array}{c}\text { Dielectric } \\
\text { constant } \boldsymbol{\varepsilon}\end{array}$ \\
\hline $\begin{array}{c}\text { Bisphenol- A } \\
\text { (Without any fibers) }\end{array}$ & 145 & 461.55 & 21.917 & 7.075 \\
\hline \multicolumn{5}{|c|}{ Bisphenol-A resin after reinforcement of PALF in different lengths. } \\
\hline $\mathbf{2}$ & 146 & 464.784 & 21.75 & 7.02 \\
\hline $\mathbf{4}$ & 154 & 490.183 & 20.636 & 6.662 \\
\hline $\mathbf{6}$ & 160 & 509.358 & 19.86 & 6.41 \\
\hline $\mathbf{8}$ & 166 & 528.447 & 19.144 & 6.18 \\
\hline $\mathbf{1 0}$ & 176 & 560.24 & 18.056 & 5.829 \\
\hline $\mathbf{1 2}$ & 185 & 588.861 & 17.18 & 5.546 \\
\hline $\mathbf{1 4}$ & 200 & 636.062 & 15.89 & 5.129 \\
\hline
\end{tabular}

Electrical resistance and inductance increases gradually as fiber length increases. The maximum value of $200 \mathrm{M} \Omega$ and $636.062 \mathrm{kH}$ respectively is obtained for composite with fiber length of $14 \mathrm{~mm}$, which is $37.93 \%$ and $37.81 \%$ respectively greater than unreinforced resin material. Similarly, Capacitance and Dielectric constant decreases gradually as fiber length increases. The minimum value of $15.89 \mathrm{pF}$ and 5.129 respectively is obtained for composite with fiber length of $14 \mathrm{~mm}$, which is $27.67 \%$ and $27.50 \%$ respectively lesser than unreinforced resin material. As fiber length increases electrical resistance of composite material also increases due to collisions of adjacent atoms and electrons as there is a larger distance to travel along the fibers. The longer the length of fiber the more will be the collisions and hence higher the resistance and lower will be the rate of current change [11]. Hence, inductance increases with increase of fiber length. Resistance is inversely proportional to capacitance, capacitance decreases with increase of resistance and fiber lengths.

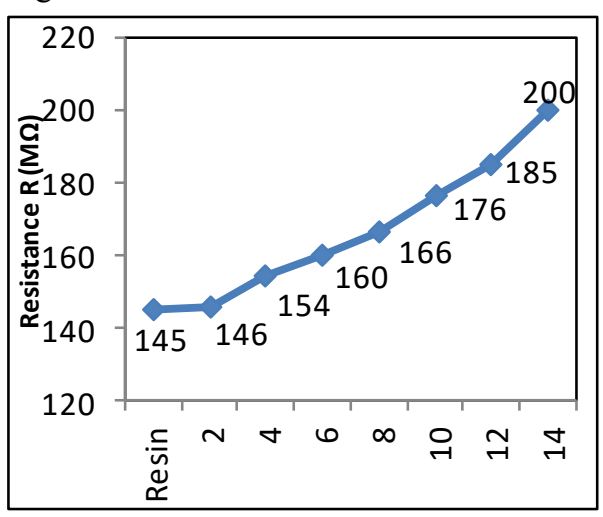

Fig. 6. Change in resistance for the resin \& composite for different fiber length

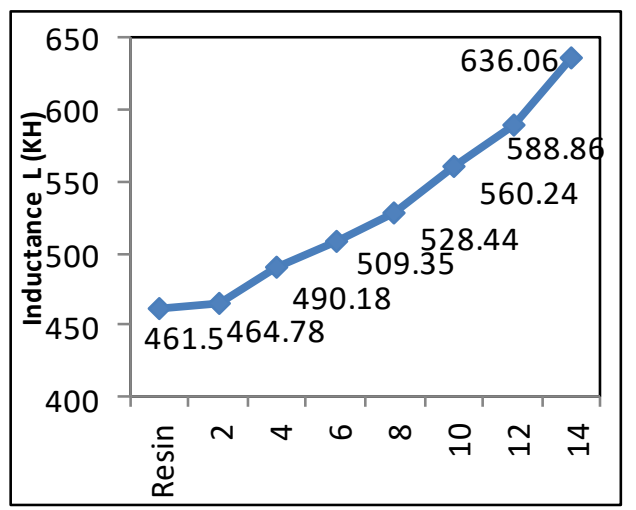

Fig. 7. Change in inductance for the resin \& composite for different fiber length 


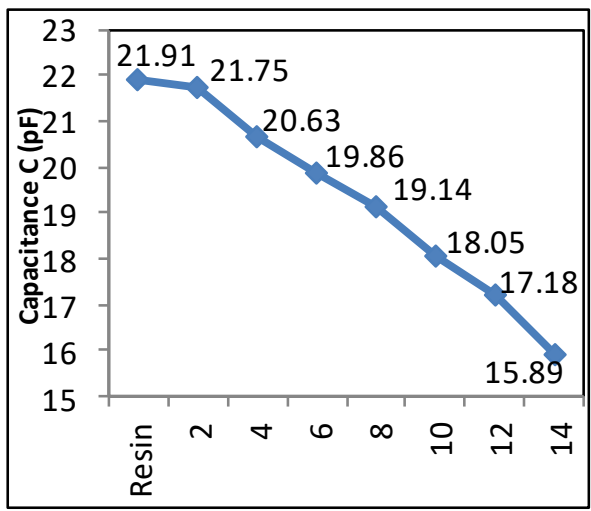

Fig. 8. Change in capacitance for the resin \& composite for different fiber length

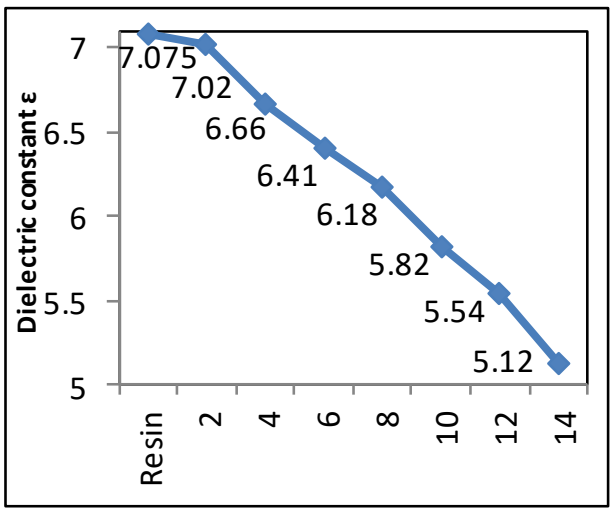

Fig. 9. Change in dielectric constant for the resin \& composite for different fiber length

As the fiber length increases for constant loading, the number of interfaces and polar $\mathrm{OH}$ groups decreases. Also alkaline treatment of the fibers after extraction from its leaf for removal of impurities and fatties is also responsible for decrease in orientation polarization. Sodium hydroxide $(\mathrm{NaOH})$ in alkaline solution reduces the chance of interface of polar $-\mathrm{OH}$ groups of lignocellulosic fibers with that of water molecules, hence reduce the ability of fiber to absorb water and dielectric constant value [12].

\section{Conclusion}

From this present work, it is observed that fiber orientations and fiber lengths significantly influences the electrical properties of PALF reinforced Bisphenol-A composite. The composite with $45^{\circ}$ orientation of fibers shows highest value of resistance and inductance and lowest values of capacitance and dielectric constant. As the fiber length increases resistance and inductance of the PALF composite increases gradually. Similarly, capacitance and dielectric constant decreases gradually. The composite with fiber length of $14 \mathrm{~mm}$ shows highest value of resistance and inductance and lowest values of capacitance and dielectric constant. Hence, PALF reinforced composite materials can be successfully used for several electrical applications.

\section{References}

1. Drzal, L.T., Mohanty, A.K., Burgueño, R. and Misra, M. "Biobased Structural Composite Materials for Housing and Infrastructure Applications: Opportunities and Challenges". Composite Science and Technology, 2003, PP.129-140.

2. Navin Chand, Deepak Jain. "Effect of Sisal Fibre Orientation on Electrical Properties of Sisal Fibre Reinforced Epoxy Composites". Elsevier Composites Part A 36, 16 August, 2004, pp. 594-602.

3. Navin Chand, Deepak Jain, Archana Nigrawal, "Investigations on gradient a.c. conductivity characteristics of bamboo (Dendrocalamus strictus)", Bull. Material Science, Volume. 29, Issue No. 2, April 2006, pp. 193-196.

4. P. A. Sreekumar, Jean Marc Saiter, Kuruvilla Joseph, G. Unnikrishnan, Sabu Thomas. "Electrical Properties of Short Sisal Fiber Reinforced Polyester Composites 
Fabricated By Resin Transfer Molding”. Elsevier Composites: Part A 43, Nov-2012, pp. 507-511.

5. Govardhan Goud and R N Rao. "Mechanical and electrical performance of Roystonea regia/glass fibre reinforced epoxy hybrid composites", Bull. Material Science, Volume 35, Issue No. 4, August 2012, pp. 595-599.

6. Uma Devi, L., Bhagawan, S.S. and Thomas, S. "Mechanical Properties Of Pineapple Leaf Fiber-Reinforced Polyester Composites". Journal of Applied Polymer Science. Nov-1996, pp. 1739-1748.

7. "Bisphenol-A: A safety and handling guide". Publication Number: AE-154. July 1997.

8. D. Pathania and D. Singh. "A review on electrical properties of fiber reinforced polymer Composites", International Journal of Theoretical \& Applied Sciences, ISSN :0975-1718, 2009, pp. 34-37

9. J. P. Siregar, S. M. Sapuan, M. Z. A. Rahman and H. M. D. K. Zaman. "The Effect of Alkali Treatment on the Mechanical Properties of Short Pineapple Leaf Fibre (PALF) Reinforced High Impact Polystyrene (HIPS) Composites". Journal of Food, Agriculture \& Environment, Volume 8, Issue 2, 2010, pp. 1103 - 1108.

10. G. George, K. Joseph, E.R. Nagarajan, E. Tomlal Jose, K.C. George, "Dielectric behaviour of PP/jute yarn commingled composites: Effect of fibre content, chemical treatments, temperature and moisture" Composites Part A: Applied Science and Manufacturing, Volume 47, April 2013 pp: 12-21.

11. N.M. Mehta and P.H. Parsania, "Fabrication and evaluation of some mechanical and electrical properties of jute-biomass based hybrid composites" Journal of Applied Polymer Science, Volume 100, Issue 3, May 2006, pp: 1754-1758.

12. Elammaran Jayamani, Sinin Hamdan, Md Rezaur Rahman, and Muhammad Khusairy Bin Bakri, "Comparative Study of Dielectric Properties of Hybrid Natural Fiber Composites", 12 ${ }^{\text {th }}$ Global Congress on Manufacturing and Management, GCMM 2014, ScienceDirect, Procedia Engineering 97, 2014, pp: 536 - 544.

13. A.S. Singha, A.K. Rana, R.K. Jarial, "Mechanical, dielectric and thermal properties of Grewia optiva fibers reinforced unsaturated polyester matrix based composites" Materials \& Design, Volume 51, 2013, pp: 924-934.

14. Z.N. Azwa, B.F. Yousif, A.C. Manalo, W. Karunasena, A review on the degradability of polymeric composites based on natural fibres, Materials \& Design, Volume 47, 2013, pp: 424-442. 